\title{
ANÁLISE SWOT E TURISMO: UMA AVALIAÇÃO ESTRATÉGICA NO PROJETO GEOPARQUE SERIDÓ/RN
}

\author{
SWOT ANALYSIS AND TOURISM: A STRATEGIC EVALUATION ON THE \\ SERIDÓ/RN GEOPARK PROJECT
}

\author{
Janaina Luciana de Medeiros ${ }^{\mathrm{a}}$ \\ Marcos Antonio Leite do Nascimento ${ }^{b}$ \\ André Riani Costa Perinotto ${ }^{c}$
}

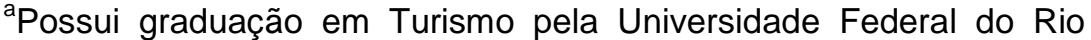
Grande do Norte, Currais Novos, Brasil(2013); Especialização em Gestão Pública Municipal pela Universidade Federal da Paraíba, Campina Grande,Brasil(2014); Especialização em UNIAFRO, Política de Promoção da Igualdade Racial, pela Universidade Federal do Semiárido, Mossoró, Brasil(2015); Mestrado em Turismo pela Universidade Federal do Rio Grande do Norte, Natal, Brasil(2015). Tem experiência na área de Turismo e Educação Ambienta, Planejamento Turístico, Gestão Pública Municipal. E-mail: janaina_ufrn_turismo@hotmail.com
\end{abstract}

${ }^{\mathrm{b}}$ Possui Graduação em Geologia pela Universidade Federal do Rio Grande do Norte, Natal, Brasil(1998); Mestrado(2000) e Doutorado (2003) em Geodinâmica pela Pó-Graduação em Geodinâmica e Geofísica da Universidade Federal do Rio Grande do Norte. Atua como Professor Efetivo (Full Professor) adjunto IV no Departamento de Geologia da Universidade Federal do Rio Grande do Norte, Natal, Brasil. Tem experiências na área de Geodiversidade, Geoconservação, Geoturismo e Geoparque, com projetos, livros e inúmeros artigos publicados sobre esses temas.

\footnotetext{
'Possui Graduação em Turismo pela Universidade Metodista de Piracicaba, Piracicaba, Brasil,(2002); Especialização em Docência para Ensino Superior em Turismo e Hotelaria pelo SENAC/SP, São Paulo, Brasil(2004); ,Mestrado em Geografia (ORGANIZAÇÃO DO ESPAÇO) pela Universidade Estadual Paulista Júlio de Mesquita Filho, Rio Claro, Brasil,(2006); Doutorado em Ciências da Comunicação( Processos Midiáticos) pela Universidade do Vale do Rio dos Sinos, São Leopoldo, Brasil, (2003). Atua como Professor Efetivo (Full Professor) da Universidade Federal do Piauí, Parnaíba, Brasil e Professor Permanente do Mestrado em Gestão de Negócios Turísticos da Universidade Estadual do Ceará, Fortaleza, Brasil. Tem Experiências na área de Turismo e Comunicação, Ensino Superior e Turismo, Marketing Turístico, Turismo e Mídias.
}

Recebido em: 14/03/2017 I Aceito em: 07/06/2017

Ciência e Sustentabilidade - CeS / Juazeiro do Norte, v. 3, n. 1, p.94-123, jan/jun 2017 I ISSN 2447-4606 


\section{RESUMO}

Este artigo focaliza a relação da análise SWOT com a atividade turística através de uma avaliação estratégica no Projeto Geoparque Seridó/RN. O projeto é composto, atualmente, pelos municípios de Cerro Corá, Lagoa Nova, Currais Novos, Acari, Carnaúba dos Dantas e Parelhas. Inicialmente foi feito o trabalho de obtenção de dados destes municípios, cuja pesquisa tem natureza exploratória, com base descritiva através do método da observação individual em campo, como também informações retiradas das entrevistas aplicadas aos sujeitos, que são os representantes das secretarias de turismo e de meio ambiente de seis municípios do referido projeto (Cerro Corá, Lagoa Nova, Currais Novos, Acari, Carnaúba dos Dantas e Parelhas), como também representantes de agências de viagens e outros profissionais que conhecem a prática do turismo na região do Seridó. Em seguida foi realizada a Matriz de Avaliação Estratégica, através da Análise SWOT, dos geossítios que integram o projeto. A partir da elaboração das matrizes de avaliação estratégica dos municípios do Projeto Geoparque Seridó, em forma de SWOT, evidenciou-se que, ao recorrer à análise e caracterização dos fatores expostos nessas matrizes, foi possível obter um diagnóstico contemplando a capacidade e a necessidade de intervenção desses elementos nos locais estudados, possibilitando levantar as potencialidades turísticas das localidades sob uma ótica mais ampliada sobre o que está acontecendo e como se encontram os geossítios e sua relação com o turismo até o presente momento.

Palavras-chave: Projeto Geoparque Seridó. Geossítios. Análise Swot. Turismo. Matriz estratégica.

\section{ABSTRACT}

This article focuses on the relation of SWOT analysis with the tourism activities through a strategic evaluation on the Seridó/RN Geopark Project. The project is composed, at presente time, by the municipalities of Cerro Corá, Lagoa Nova, CurraisNovos, Acari, Carnaúba dos Dantas and Parelhas. It was initially made the data retrieval work from these municipalities, whose research is exploratory, with a descriptive basis through individual observation method in field, as well as information taken from interviews applied to the subjects who are the representatives of the tourism and environment secretaries of six municipalities of the related project (Cerro Corá, Lagoa Nova, Currais Novos, Acari , Carnaúba dos Dantas and Parelhas), as well as representatives of travel agencies and other professionals who know the practice of tourism in Seridó region. Then, the strategic evaluation matrix was made, through the SWOT analysis, on the geosites that integrate the project. From the elaboration of strategic evaluation matrices of the municipalities in the SeridóGeopark Project, by the SWOT format, it was evidenced that, by the analysis and characterization of the factors exposed in these matrices, it was possible to get a diagnosis comprehending the capacity and the need of intervention of these elements in the locations under study, making possible to survey the tourist potential of the locations under a more expanded optics about what is going on and how are the geosites and their relation with tourism up to the present moment.

Keywords: Seridó Geopark Project. Geosites. Swot Analysis. Tourism. Strategic matrix. 


\section{INTRODUÇÃO}

O turismo pode ser definido como o conjunto de atividades realizadas, em busca do lazer, isto perante algum tipo de deslocamento que necessariamente não seja seu lugar de origem e que essas viagens não envolvam alguma outra motivação que não o lazer para a sua realização.

Dessa forma, nas regiões que pretendem trabalhar com o turismo, devese existir uma preocupação com o planejamento para divulgar e comercializar seu produto turístico de forma sustentável, diminuindo, com isso, os impactos causados por essa atividade.

Sendo assim, é fundamental considerar o fortalecimento do turismo através da inter-relação entre todos os setores envolvidos na atividade, sejam eles: o poder público, o empresariado, os profissionais turísticos, os residentes e os visitantes.

Este fortalecimento deve ser planejado de forma equilibrada e considerando a colaboração mútua de forma a possibilitar que o trabalho proporcione um resultado satisfatório a todos. Através desta união, dos setores e das ciências, a atividade passa a se desenvolver de modo que as informações sobre questões ambientais, sociais e econômicas sejam mais perceptíveis e acessíveis, fazendo com que a atividade turística, tenha possibilidade de fazer parte do cotidiano comunitário, conduzindo e priorizando a educação como uma forma de comportamento estratégico e sustentável dessa localidade.

O presente artigo focaliza a relação da análise SWOT com a atividade turística através de uma avaliação estratégica no Projeto Geoparque Seridó/RN.

Cabe ressaltar que, o projeto supracitado é composto, atualmente, pelos municípios de Cerro Corá, Lagoa Nova, Currais Novos, Acari, Carnaúba dos Dantas e Parelhas, localizados na Mesorregião Central do Rio Grande do Norte, mais especificamente na porção centro-meridional do Estado, tendo o acesso a partir de Natal, capital do Estado do Rio Grande do Norte, pela BR226 até a cidade de Currais Novos, tomando-se em seguida outras rodovias (BR-104 e BR-427) e (RN-087 e RN-288) para ter acesso aos demais municípios da área. 


\section{MATERIAIS E MÉTODOS}

Inicialmente foi realizado o trabalho para obtenção de dados, ou seja, pesquisa documental sobre os municípios que fazem parte do Projeto Geoparque Seridó de forma a melhor compreender a realidade de usabilidade turística do local baseando-se nos conceitos direcionados para a prática sustentável como ferramenta de implementação do turismo.

A presente pesquisa teve, ainda, natureza exploratória. Além disso, o estudo possuiu base descritiva das características obtidas por meio do método da observação das localidades selecionadas.

Quanto aos meios, o trabalho foi de campo, com a aplicação de entrevista com os sujeitos dessa pesquisa, que foramos representantes das secretarias de turismo e de meio ambiente de seis municípios do Projeto Geoparque Seridó (Cerro Corá, Lagoa Nova, Currais Novos, Acari, Carnaúba dos Dantas e Parelhas,), assim como, representantes de agências de viagens, além de profissionais que conhecem a prática do turismo na região do Seridó, com a finalidade de obter informações que proporcionaram maior conhecimento sobre o objeto de pesquisa, bem como também representantes das comunidades nos quais estão inseridosnas áreas dos geossítios estudados.

A presente pesquisa também buscouelencar as potencialidades, entraves e prioridades para a realização de uma prática turística em prol de um desenvolvimento sustentável, para isso foi feita a Matriz de Avaliação Estratégica, aplicada através da análise SWOT.

Vale ressaltar, ainda, que, os fatores que compuseram essa Matriz de Avaliação Estratégica, em forma de SWOT, vieram das respostas obtidas nas entrevistas realizadas com os sujeitos dessa pesquisa, assim como, na observação feita através da pesquisa de campo.

Assim, foram atribuídas notas para a ponderação na Matriz SWOT para que se cruzem os pontos fortes versus oportunidades, pontos fortes contraas ameaças, pontos fracos contrapondo asoportunidades, e pontos fracos versusameaças, com a finalidade de se extrair quais os pontos fortes e as oportunidades são as forças impulsoras que fortalecem os geossítios, e quais o 
conjunto dos pontos fracos e das ameaças se constituem nas forças restritivas que poderão interferir no desenvolvimento do turismo de forma sustentável nesses locais (BANZATO et. al, 2012).

Por fatores internos entende-se, por conseguinte - Pontos fracos: fenômenos ou condições inerentes ao recorte espacial do presente estudo, que comprometem ou dificultam seu desenvolvimento; Pontos fortes: fenômenos ou condições que contribuam ou favoreçam seu manejo; Ameaças: fenômenos ou condições externas a área estudada, que comprometem ou dificultam o alcance de seus objetivos; Oportunidades: fenômenos ou condições externas que contribuem para o alcance de seus objetivos. Em que o conjunto desses pontos fracos e das ameaças se constituem nas forças restritivas que debilitam a região comprometendo seu desenvolvimento (BANZATO et. al, 2012). E as notas atribuídas foram: Nota 0 - intensidade nula ou baixa; nota 1 intensidade média; nota 2 - intensidade alta.

Desse modo, a leitura dessas Matrizes da Avaliação Estratégica, em forma de SWOT, no tocante as potencialidades do cenário interno se dará no somatório das linhas horizontais, que resultará nas forças mais atuantes e as fraquezas mais debilitantes. O diagnóstico externo será visto no somatório das linhas verticais, ou seja, nas colunas identificando as oportunidades mais acessíveis e as ameaças mais impactantes (BANZATO, et. al., 2012).

Foi realizada a Matriz de Avaliação Estratégica, porquanto, em forma de construção da Análise SWOT, dos geossítios que integram o projeto de criação do Geoparque Seridó, na qual a caracterização dos sujeitos da pesquisa se compôs na delimitação desses geossítios, a fim de alcançar os objetivos propostos, em que será possível identificar os pontos fortes e fracos em relação à prática turística sustentável do local e, assim, propor melhorias através da inserção da educação ambiental voltada a geodiversidade, que devem ser realizadas visando à sustentabilidade dos locais.

\section{ANÁLISE SWOT E TURISMO}


A Análise SWOT, segundo Dantas e Melo (2008), é um sistema simples utilizado para posicionar ou verificar a posição estratégica da empresa ou, neste caso, de um destino, localidade, ou região em questão, sendo uma sigla oriunda do inglês e é um acrônimo de Forças, Fraquezas, Oportunidades e Ameaças. Outrossim, essa metodologia tornou-se uma ferramenta ideal no processo de gestão e monitoramento do turismo de uma determinada localidade, tendo sua autoria creditada a dois professores da Havard Business School: Kenneth Andrews e Roland Christense.

Os fundamentos da Análise SWOT datam dos anos 1950, sendo Peter Drucker o primeiro autor a levantar esta problemática, e posteriormente, essa análise foi desenvolvida por vários autores, como, por exemplo Igor Ansoff (1965), Kenneth Andrews (1971) e Henry Mintzberg (1973). Contudo, como exposto no parágrafo anterior, essa análise foi essencialmente desenvolvida pela Escola de Harvard dando a base da formulação estratégica das décadas seguintes (FONSECA, 2010).

A Matriz SWOT se desenvolveu, por conseguinte, nos anos 1960, na escola de Administração Geral da Havard Business School, com o objetivo de reunir o ambiente interno da organização com suas expectativas externas e de focalizar a combinação das forças e fraquezas de uma organização com as oportunidades e ameaças provenientes do cenário o qual a organização pertencia (MINTZBERG, 2000; SILVEIRA, 2002).

E neste sentido "os pontos fortes de uma organização estão de acordo com os fatores críticos de sucesso para satisfazer as oportunidades de mercado, a empresa será competitiva a longo prazo" (TRAPP, 2005, p. 36).

Segundo Mintzberg (2000), a Análise SWOT permite unicamente uma adequação entre as possibilidades externas e as capacidades internas, não identificando com clareza as forças e fraquezas da organização, nem a integração entre os objetivos estratégicos.

Contudo, o segredo nesse tipo de análise está em sempre mudar internamente, de modo que as forças possam ser desenvolvidas a fim de minimizar as ameaças e maximizar as oportunidades (DUBRIN, 1998; TRAPP, 2005).

Lobato (2004) descreve as oportunidades como sendo as situações ou acontecimentos relacionados ao ambiente externo da organização que podem 
contribuir positivamente para o exercício de sua missão e a concretização de sua visão.

Entende-se, porquanto, que a análise estratégica usando o método da Análise SWOT é um instrumento de fácil aplicação para auxiliar no planejamento das atividades estratégicas de uma determinada região.

Deste modo, a avaliação da SWOT, com base no modelo de Porter (1980) deveria atender tanto à plausibilidade, como a consistência dos componentes, ponderando a interação entre aenvolventeexterna (macro ambienteeambiente competitivo) einterna(vantagenscompetitivas e sua sustentabilidade, na medida em que, no final surgissem resultados satisfatórios) (TEIXEIRA, 2005; FONSECA, 2010).

Diante disso pode-se observar que a SWOT fornece uma orientação estratégica significativa, pois permite segundo Machado (2005) e Alves et. al. (2007):Eliminar pontos fracos nas áreas pelas quais a empresa enfrenta ameaças graves da concorrência e tendências desfavoráveis perante 0 negócio;Compreender oportunidades descobertas a partir de seus pontos fortes;Corrigir pontos fracos nas áreas em que a organização vislumbra oportunidades potenciais e;Monitorar áreas onde a organização possui pontos fortes afim de não ser surpreendida futuramente por possíveis riscos e incertezas.

Ressalta-se ainda que, devido "a simplicidade de aplicação, tanto para empresas, como para, produtos e serviços, o modelo SWOT, é amplamente usado em forma de matriz" (ALVES, et. al., 2007, p. 28), pois assim fica demonstrado a situação atual desse determinado local de maneira simples e de fácil entendimento.

A utilização da SWOT para o planejamento da atividade turística se constitui, portanto, como um ato de planejar afim de, organizar, dirigir e controlar através da gestão uma situação favorável a essa prática, onde "a administração do turismo lida com o comportamento das pessoas e das instituições humanas, em meio a um permanente e inexorável processo de mudança” (PETROCCHI, 2001, p. 97).

A utilização da Análise SWOT por parte dos gestores que pretendem trabalhar o turismo está, portanto, de acordo com a premissa da sustentabilidade, e permanência no mercado de forma competitiva torna-se 
importante, pois a identificação de seus pontos fortese fracos permitirá que a gestão tome medidas que maximizem os efeitos dos seus pontosfortes e a minimização dos efeitos dos pontos fracos (AZEVEDO; COSTA, 2001; LOUREIRO, 2011).

Além disso, a identificação das oportunidades e ameaças existentes no mercado fará com que esses gestores possam aproveitar as oportunidades existentes e fazer face às ameaças que surgirem, e com isso, construir estratégias concordantes nos seus pontos fortes, minimizando os efeitos negativos dos fracos, explorando as oportunidades do mercado e protegendose das ameaças (AZEVEDO e COSTA, 2001; LOUREIRO, 2011).

\section{ANÁLISE ESTRATÉGICA NO PROJETO GEOPARQUE SERIDÓ/RN}

\subsection{Elaboração da matriz de Avaliação Estratégica no Projeto Geoparque Seridó}

A Matriz de Avaliação Estratégica, em forma de Análise SWOT, constituiu, portanto, uma análise da situação geral dos geossítios inseridos nos municípios: Cerro Corá, Lagoa Nova, Currais Novos, Acari, Parelhas, Carnaúba dos Dantas, que estão no Projeto Geoparque Seridó, com relação aos fatores internos e externos que impulsionam ou dificultam a consecução da prática geoturística nessas localidades.

Com isso, foram sistematizados os fatores evidenciados na pesquisa, em junção com o método citado, em que foram agrupados em uma tabela contendo os pontos fracos, pontos fortes, ameaças e oportunidades.

A seguir, dados com as abreviações (Quadro 1) inseridos na Matriz de Avaliação Estratégica, em forma de Análise SWOT, dos referidos geossítios para um melhor entendimento dos dados inseridos.

Quadro 1: Abreviações inseridas na Matriz de Avaliação Estratégica, em forma de Matriz SWOT, dos geossítios 


\begin{tabular}{|c|c|}
\hline PGE & PotencialGeoturístico e Ecoturística \\
\hline DP & Desenvolvimento da Pesquisa \\
\hline IAG & Integração com outras Áreas Geoturísticas \\
\hline USA & UsoSustentável da Area \\
\hline GR & Geração de Renda \\
\hline ACA & Aumento da ConscientizaçãoAmbiental \\
\hline CA & Conservação da Area \\
\hline CP & Capacitação de Profissionais \\
\hline OIC & Ocupação Irregular Constante \\
\hline EI & Especulaçãolmobiliária \\
\hline E & Extrativismo \\
\hline ICG & Ignorância sobre a Conservação de Geossítios \\
\hline INC & InteressesNãoConservacionistas \\
\hline TD & TurismoDesordenado \\
\hline
\end{tabular}

Fonte: Dados da pesquisa, 2015.

A seguir estão expostas as Matrizes de Avaliação Estratégica, em forma de Análise SWOT dos geossítios e seus respectivos municípios, relatando quais as forças mais atuantes, fraquezas mais debilitantes, do cenário interno; e quais as oportunidades mais acessíveis, e ameaças mais importantes do cenário externo para o desenvolvimento da atividade geoturística dessa região.

\subsubsection{Matriz deAvaliação Estratégica de Cerro Corá}

Abaixo a Tabela 1, para a área referente ao geossítios Serra Verde; Cruzeiro de Cerro Corá; Vale Vulcânico, todos localizados em Cerro Corá(RN).

Tabela 1: Matriz de avaliação estratégica dos geossítios localizados em Cerro Corá.

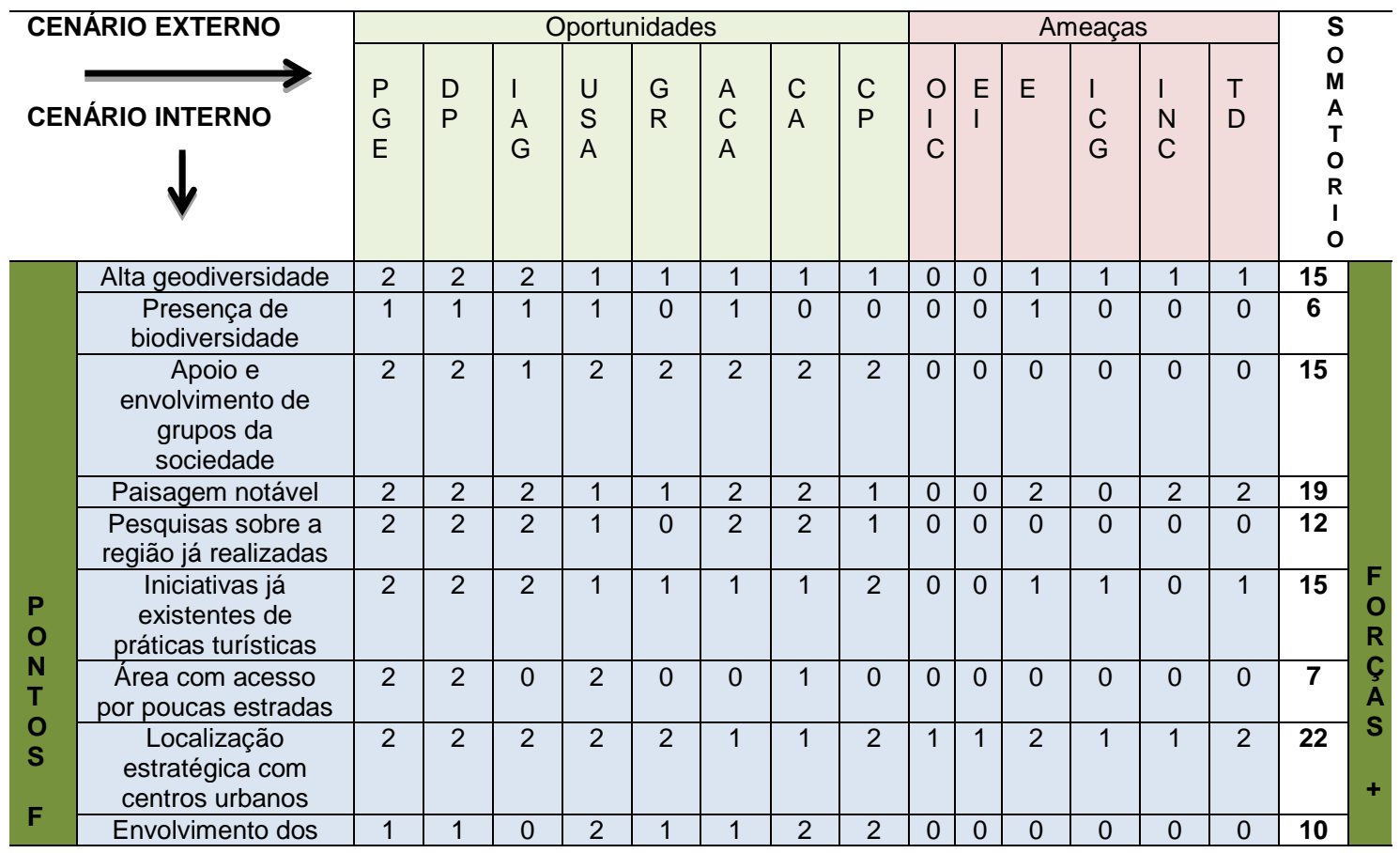

Ciência e Sustentabilidade - CeS / Juazeiro do Norte, v. 3, n. 1, p. 94-123, jan/jun 2017 


\begin{tabular}{|c|c|c|c|c|c|c|c|c|c|c|c|c|c|c|c|c|c|}
\hline 0 & gestores públicos & & & & & & & & & & & & & & & & $\bar{A}$ \\
\hline $\begin{array}{l}R \\
T \\
E\end{array}$ & $\begin{array}{c}\text { Presença de } \\
\text { atributos histórico- } \\
\text { culturais }\end{array}$ & 2 & 2 & 2 & 2 & 1 & 2 & 2 & 1 & 0 & 0 & 2 & 0 & 1 & 1 & 18 & $\begin{array}{l}\text { T } \\
\text { U } \\
\text { A }\end{array}$ \\
\hline $\mathbf{S}$ & $\begin{array}{l}\text { Conectividade com } \\
\text { outros geossítios }\end{array}$ & 2 & 2 & 2 & 2 & 1 & 1 & 2 & 1 & 0 & 0 & 0 & 0 & 0 & 0 & 13 & $\begin{array}{l}N \\
T\end{array}$ \\
\hline & $\begin{array}{c}\text { Acesso da } \\
\text { comunidade à } \\
\text { educação ambiental }\end{array}$ & 2 & 2 & 1 & 2 & 0 & 2 & 2 & 0 & 0 & 0 & 0 & 0 & 0 & 0 & 11 & $\begin{array}{l}E \\
S\end{array}$ \\
\hline & $\begin{array}{l}\text { Valorização do } \\
\text { patrimônio } \\
\text { ambiental }\end{array}$ & 2 & 2 & 1 & 2 & 1 & 2 & 2 & 1 & 0 & 0 & 0 & 0 & 0 & 0 & 13 & \\
\hline & $\begin{array}{l}\text { Preservação dos } \\
\text { recursos naturais }\end{array}$ & 2 & 2 & 1 & 1 & 0 & 2 & 2 & 0 & 0 & 0 & 0 & 0 & 0 & 0 & 10 & \\
\hline & $\begin{array}{l}\text { Preparação às } \\
\text { emergências } \\
\text { ambientais }\end{array}$ & 1 & 1 & 0 & 0 & 0 & 0 & 0 & 2 & 0 & 0 & 0 & 0 & 0 & 0 & 4 & \\
\hline & $\begin{array}{l}\text { Presença de um } \\
\text { guia/condutor local }\end{array}$ & 2 & 2 & 2 & 2 & 1 & 1 & 2 & 2 & 0 & 0 & 0 & 0 & 0 & 0 & 14 & \\
\hline & $\begin{array}{c}\text { Gestão dos resíduos } \\
\text { sólidos }\end{array}$ & 0 & 0 & 0 & 1 & 0 & 1 & 1 & 0 & 0 & 0 & 0 & 0 & 0 & 0 & 3 & \\
\hline & Falta de fiscalização & 1 & 0 & 0 & 1 & 1 & 0 & 1 & 0 & 1 & 0 & 1 & 2 & 2 & 2 & 12 & $\mathbf{F}$ \\
\hline & $\begin{array}{l}\text { Dificuldade de } \\
\text { fiscalização }\end{array}$ & 0 & 0 & 0 & 0 & 0 & 0 & 0 & 0 & 0 & 0 & 0 & 1 & 1 & 1 & 3 & $\begin{array}{l}\mathbf{R} \\
\mathbf{A}\end{array}$ \\
\hline $\mathbf{P}$ & $\begin{array}{l}\text { Inexistência de } \\
\text { infraestrutura }\end{array}$ & 1 & 1 & 1 & 1 & 0 & 1 & 1 & 0 & 1 & 0 & 1 & 2 & 2 & 1 & 13 & $\begin{array}{l}\mathbf{Q} \\
\mathbf{U}\end{array}$ \\
\hline $\begin{array}{l}\mathbf{O} \\
N \\
T \\
0\end{array}$ & $\begin{array}{l}\text { Inexistência de } \\
\text { estudo de } \\
\text { capacidade de } \\
\text { carga }\end{array}$ & 0 & 1 & 0 & 0 & 0 & 0 & 0 & 0 & 0 & 0 & 0 & 1 & 1 & 1 & 3 & $\begin{array}{l}\text { E } \\
Z \\
\text { A } \\
\text { S }\end{array}$ \\
\hline $\mathbf{S}$ & $\begin{array}{l}\text { Ocupações } \\
\text { irregulares }\end{array}$ & 0 & 0 & 0 & 0 & 0 & 0 & 0 & 0 & 0 & 0 & 0 & 0 & 0 & 0 & 0 & + \\
\hline $\begin{array}{l}\mathbf{F} \\
\mathbf{R}\end{array}$ & $\begin{array}{c}\text { Falta de } \\
\text { acessibilidade }\end{array}$ & 1 & 0 & 0 & 1 & 0 & 0 & 1 & 0 & 0 & 0 & 0 & 0 & 0 & 0 & 3 & D \\
\hline $\begin{array}{l}\text { A } \\
\text { C } \\
0\end{array}$ & $\begin{array}{c}\text { Falta de consciência } \\
\text { ambiental }\end{array}$ & 0 & 0 & 0 & 0 & 0 & 0 & 0 & 0 & 0 & 1 & 2 & 2 & 2 & 2 & 9 & B \\
\hline S & $\begin{array}{l}\text { Falta de recursos } \\
\text { financeiros }\end{array}$ & 1 & 1 & 0 & 1 & 1 & 0 & 1 & 1 & 0 & 0 & 1 & 1 & 1 & 1 & 10 & L \\
\hline & $\begin{array}{c}\text { Falta de consciência } \\
\text { da importância da } \\
\text { área }\end{array}$ & 1 & 1 & 1 & 1 & 1 & 0 & 1 & 0 & 0 & 0 & 2 & 2 & 2 & 1 & 13 & $\begin{array}{l}\mathrm{T} \\
\mathrm{A} \\
\mathrm{N}\end{array}$ \\
\hline & $\begin{array}{l}\text { Falta de recursos } \\
\text { humanos }\end{array}$ & 0 & 1 & 1 & 1 & 1 & 1 & 1 & 1 & 0 & 0 & 1 & 1 & 1 & 1 & 11 & $\begin{array}{l}\mathrm{T} \\
\mathrm{E}\end{array}$ \\
\hline & $\begin{array}{l}\text { Morosidade do } \\
\text { poder público }\end{array}$ & 0 & 1 & 1 & 1 & 1 & 0 & 1 & 1 & 0 & 0 & 0 & 0 & 0 & 0 & 6 & $\mathbf{s}$ \\
\hline \multicolumn{2}{|r|}{ SOMATÓRIO } & 34 & 30 & 25 & 32 & 17 & 24 & 32 & 21 & 3 & 2 & 17 & 15 & 17 & 17 & & \\
\hline
\end{tabular}

Fonte: Dados da pesquisa, 2015.

De acordo a tabela acima, o que se percebeu foi que, no tocante as potencialidades do cenário interno, a força mais atuante foi:

$\checkmark$ Localização estratégica com centros urbanos (22);

$\checkmark$ E menos atuante: Gestão de Resíduos Sólidos (3).

Em relação à potencialidade apontada como fraqueza mais debilitante teve-se um empate:

$\checkmark$ Inexistência de infraestrutura (13);

$\checkmark$ Falta de consciência da importância da área (13);

$\checkmark$ E a menos: Ocupações irregulares (0).

Do ponto do cenário externo, se obtive como oportunidade mais pontuada:

$\checkmark$ Potencial geoturístico e ecoturístico (34);

Ciência e Sustentabilidade - CeS / Juazeiro do Norte, v. 3, n. 1, p. 94-123, jan/jun 2017 
$\checkmark$ E menos pontuada: Geração de Renda (17);

Referente às ameaças, tiveram três empatadas nesse critério com maior pontuação:

$\checkmark$ Extrativismo (17);

$\checkmark$ Interesses não conservacionistas (17);

$\checkmark$ Turismo desordenado (17);

$\checkmark$ E menos pontuada Especulação Imobiliária (2).

\subsubsection{Matriz de Avaliação Estratégica de Lagoa Nova}

A Tabela 2 a seguir, refere-se à Matriz de Avaliação Estratégica, em forma de análise SWOT, para a área referente ao geossítio Mirante Santa Rita localizado em Lagoa Nova (RN).

Tabela 2: Matriz de avaliação estratégica de Lagoa Nova.

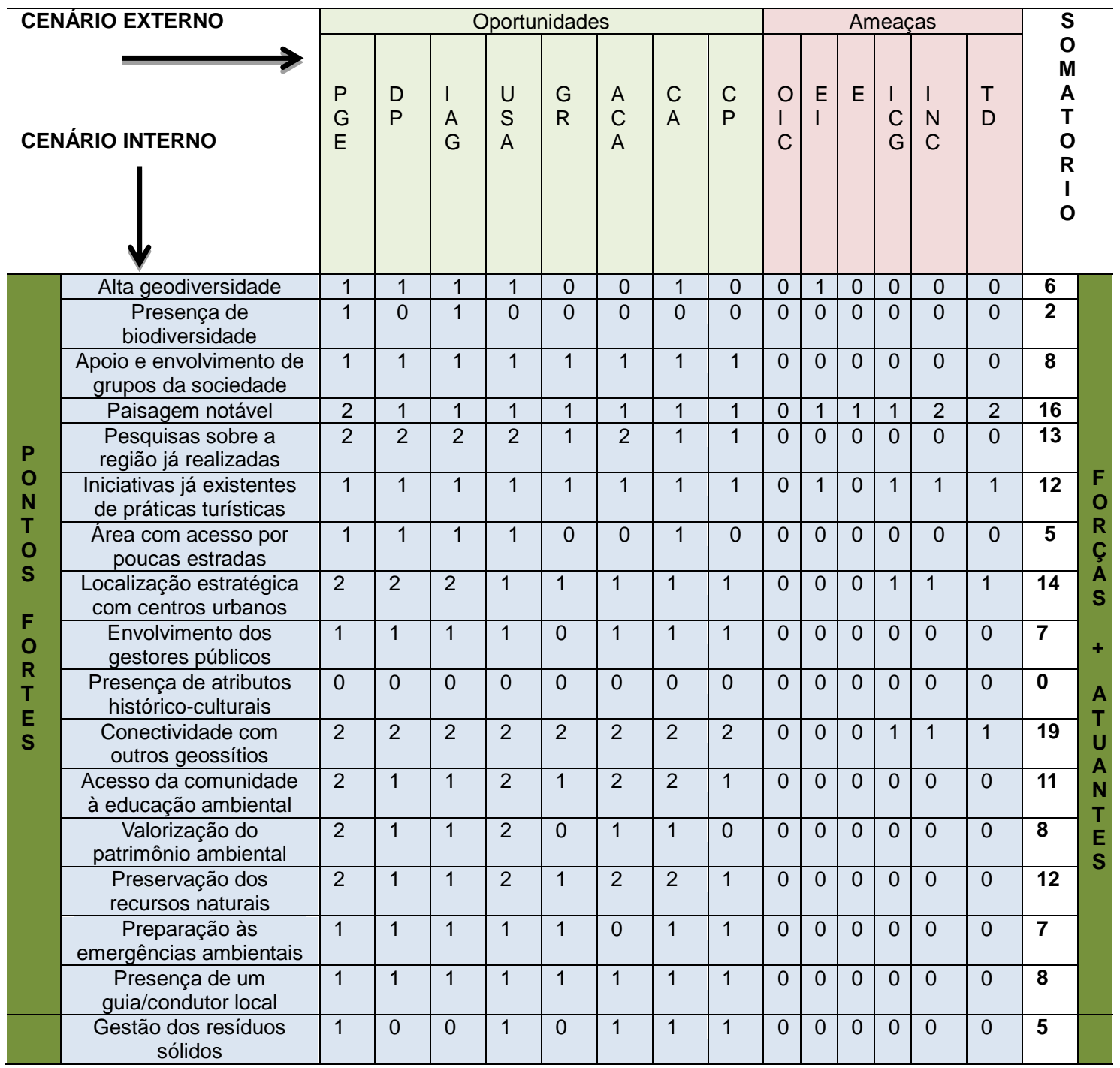




\begin{tabular}{|c|c|c|c|c|c|c|c|c|c|c|c|c|c|c|c|c|c|}
\hline $\mathbf{P}$ & Falta de fiscalização & 0 & 0 & 0 & 0 & 0 & 0 & 0 & 0 & 1 & 1 & 0 & 2 & 2 & 2 & 8 & $\mathbf{F}$ \\
\hline $\begin{array}{l}\mathbf{O} \\
\mathbf{N}\end{array}$ & $\begin{array}{l}\text { Dificuldade de } \\
\text { fiscalização }\end{array}$ & 0 & 0 & 0 & 0 & 0 & 0 & 0 & 0 & 0 & 0 & 0 & 1 & 1 & 1 & 3 & $\begin{array}{l}\mathbf{R} \\
\mathbf{A}\end{array}$ \\
\hline $\begin{array}{l}\text { T } \\
0\end{array}$ & $\begin{array}{l}\text { Inexistência de } \\
\text { infraestrutura }\end{array}$ & 0 & 0 & 0 & 0 & 1 & 0 & 0 & 0 & 0 & 0 & 0 & 0 & 0 & 0 & 1 & $\begin{array}{l}Q \\
U\end{array}$ \\
\hline $\mathbf{S}$ & $\begin{array}{l}\text { Inexistência de estudo } \\
\text { de capacidade de carga }\end{array}$ & 1 & 1 & 0 & 0 & 0 & 0 & 0 & 1 & 0 & 0 & 0 & 0 & 1 & 2 & 6 & $\begin{array}{l}E \\
Z\end{array}$ \\
\hline $\begin{array}{l}\mathbf{F} \\
\mathbf{R}\end{array}$ & Ocupações irregulares & 1 & 1 & 0 & 1 & 0 & 0 & 1 & 0 & 0 & 1 & 0 & 1 & 1 & 0 & 7 & $\begin{array}{l}A \\
S\end{array}$ \\
\hline $\begin{array}{l}\text { A } \\
\text { C }\end{array}$ & Falta de acessibilidade & 1 & 1 & 0 & 0 & 0 & 0 & 1 & 0 & 0 & 0 & 0 & 0 & 0 & 0 & 3 & $\begin{array}{l}+ \\
\text { D }\end{array}$ \\
\hline $\begin{array}{l}0 \\
S\end{array}$ & $\begin{array}{c}\text { Falta de consciência } \\
\text { ambiental }\end{array}$ & 1 & 0 & 0 & 2 & 0 & 2 & 2 & 0 & 0 & 0 & 1 & 0 & 1 & 1 & 10 & B \\
\hline & $\begin{array}{l}\text { Falta de recursos } \\
\text { financeiros }\end{array}$ & 0 & 1 & 0 & 0 & 1 & 0 & 0 & 1 & 0 & 0 & 0 & 0 & 0 & 1 & 4 & L \\
\hline & $\begin{array}{l}\text { Falta de consciência da } \\
\text { importância da área }\end{array}$ & 1 & 1 & 1 & 1 & 1 & 0 & 1 & 1 & 0 & 1 & 0 & 1 & 1 & 1 & 11 & $\begin{array}{l}\mathbf{T} \\
\mathbf{A}\end{array}$ \\
\hline & $\begin{array}{c}\text { Falta de recursos } \\
\text { humanos }\end{array}$ & 1 & 1 & 0 & 0 & 0 & 0 & 1 & 0 & 0 & 0 & 0 & 0 & 1 & 1 & 5 & $\begin{array}{l}N \\
T\end{array}$ \\
\hline & $\begin{array}{l}\text { Morosidade do poder } \\
\text { público }\end{array}$ & 0 & 0 & 0 & 1 & 1 & 0 & 1 & 1 & 0 & 0 & 0 & 0 & 0 & 1 & 5 & $\begin{array}{l}E \\
S\end{array}$ \\
\hline & SOMATÓRIO & 29 & 23 & 19 & 25 & 15 & 18 & 25 & 17 & 1 & 6 & 2 & 9 & 13 & 15 & & \\
\hline & & & & & & & & & & & & $\begin{array}{l}\text { nea } \\
\text { impc }\end{array}$ & $\begin{array}{l}\text { ças } \\
\text { ortar }\end{array}$ & $\begin{array}{l}\text { mais } \\
\text { nte }\end{array}$ & & & \\
\hline
\end{tabular}

Fonte: Dados da pesquisa, 2015.

As potencialidades do cenário interno, de acordo com a tabela 2, a forças mais atuantesforam:

$\checkmark$ Conectividade com outros geossítios (19);

$\checkmark$ E a considerada menos atuante Presença de Atributos Histórico-culturais (0).

E como a maior potencialidade apontadacomo fraqueza mais debilitante, tem-se:

$\checkmark$ Falta de consciência da importância da área (11);

$\checkmark$ Onde a menor pontuada ficou a Inexistência de Infraestrutura (1).

Em relação ao cenário externo, se obteve:

$\checkmark$ O Potencial Geoturístico e Ecoturístico (29) como a oportunidades mais pontuada;

$\checkmark$ E a Geração de Renda (15) com a menor pontuação.

E como ameaças:

$\checkmark$ OTurismodesordenado (15) obteve maior valor;

$\checkmark$ EOcupação Irregular Constante (1) com menor valor.

\subsubsection{Matriz de Avaliação Estratégica de Currais Novos}


A Matriz de Avaliação Estratégica (Tabela 3), em forma de Análise SWOT, refere- se à área referente ao geossítios Pico do Totoró, Morro do Cruzeiro, Mina Brejuí, Cânions dos Apertados, localizados em Currais Novos $(\mathrm{RN})$.

Tabela 3: Matriz de Avaliação Estratégica deCurrais Novos.



Ciência e Sustentabilidade - CeS / Juazeiro do Norte, v. 3, n. 1, p. 94-123, jan/jun 2017 


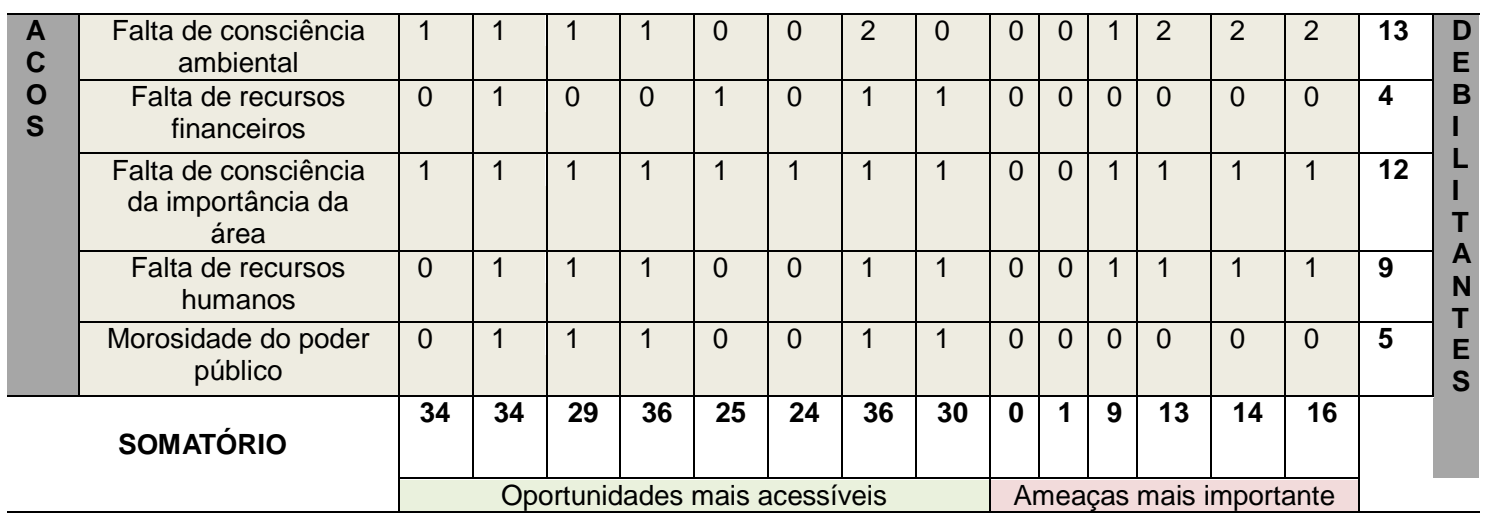

Fonte: Dados da pesquisa, 2015.

Levando em consideração a tabela 3 supracitada, pode-se afirmar que: Em relação às potencialidades do cenário interno, as cinco forças mais atuantes que receberam maior pontuação foram:

$\checkmark$ Alta geodiversidade (20); Iniciativas já existentes de práticas turísticas (17); Apoio e envolvimento de grupos da sociedade (16), Valorização do patrimônio ambiental (16), Presença de um guia/condutor local (16); Paisagem notável, Presença de atributos histórico-culturais (15); Localização estratégica com centros urbanos, Conectividade com outros geossítios (13).

Segundo as potencialidades que foram apontadas como fraquezas mais debilitantes, temos as cinco com maior pontuação:

$\checkmark$ Falta de consciência ambiental (13); Falta de consciência da importância da área (12); Falta de acessibilidade (10); Falta de recursos humanos (9); Inexistência de infraestrutura (8) e Inexistência de estudo de capacidade de carga (8).

Já as cinco mais pontuadas sobre as oportunidades do cenário externo têm:

$\checkmark$ Uso sustentável da área (36) e Conservação da área (36); Potencial geoturístico e ecoturístico (34), Desenvolvimento de pesquisa (34); Capacitação de profissionais (30); Integração com outras áreas geoturísticas (29); Geração de renda (25).

Como as cinco ameaças mais pontuadas tiveram:

$\checkmark$ Turismo desordenado (16); Interesses não conservacionistas (14); Ignorância sobre a conservação de geossítios (13); Extrativismo (9); e Especulação imobiliária (1). 


\subsubsection{Matriz de Avaliação Estratégica de Acari}

A Matriz de Avaliação Estratégica (Tabela 4), em forma de Análise SWOT, constitui área referente ao geossítios açude de gargalheiras, cruzeiro de Acari, Poço do Arroz, marmitas do Rio Carnaúba, localizados em Acari $(\mathrm{RN})$.

Tabela 4: Matriz de avaliação estratégica de Acari.

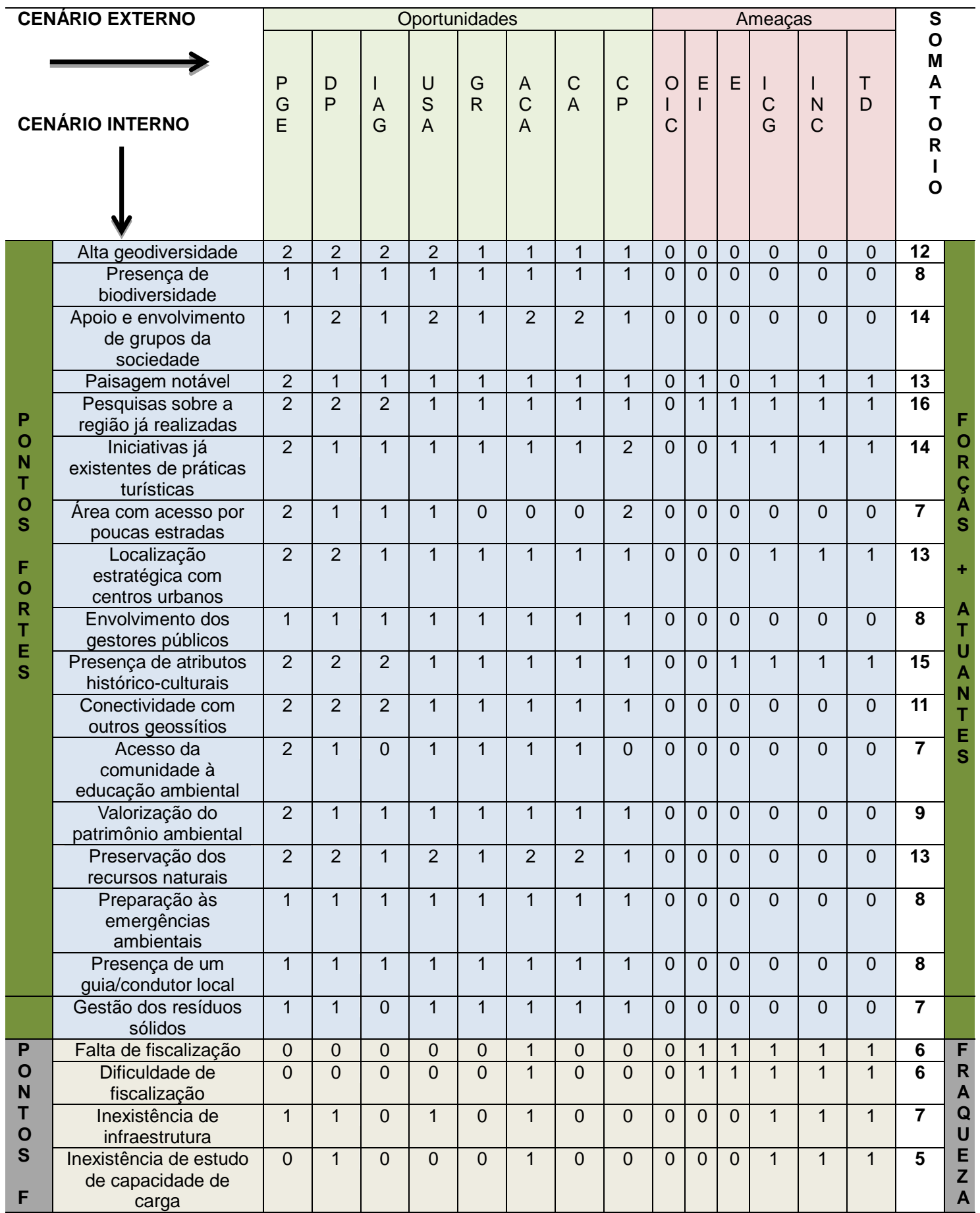

Ciência e Sustentabilidade - CeS / Juazeiro do Norte, v. 3, n. 1, p. 94-123, jan/jun 2017 
Janaina Luciana de Medeiros; Marcos Antonio Leite do Nascimento; André Riani Costa Perinotto

\begin{tabular}{|c|c|c|c|c|c|c|c|c|c|c|c|c|c|c|c|c|c|}
\hline $\mathbf{R}$ & Ocupações irregulares & 0 & 0 & 0 & 0 & 0 & 0 & 1 & 0 & 0 & 0 & 0 & 1 & 1 & 1 & 4 & S \\
\hline $\begin{array}{l}\text { C } \\
\text { o }\end{array}$ & $\begin{array}{c}\text { Falta de } \\
\text { acessibilidade }\end{array}$ & 1 & 1 & 1 & 0 & 0 & 0 & 1 & 0 & 0 & 0 & 0 & 0 & 0 & 0 & 4 & $\begin{array}{l}\text { D } \\
\text { E }\end{array}$ \\
\hline $\mathbf{s}$ & $\begin{array}{c}\text { Falta de consciência } \\
\text { ambiental }\end{array}$ & 1 & 0 & 0 & 0 & 0 & 1 & 0 & 0 & 0 & 0 & 1 & 1 & 1 & 1 & 6 & B \\
\hline & $\begin{array}{l}\text { Falta de recursos } \\
\text { financeiros }\end{array}$ & 0 & 1 & 0 & 0 & 0 & 0 & 1 & 1 & 0 & 0 & 0 & 0 & 0 & 0 & 3 & \\
\hline & $\begin{array}{l}\text { Falta de consciência } \\
\text { da importância da } \\
\text { área }\end{array}$ & 1 & 1 & 1 & 0 & 1 & 0 & 1 & 1 & 0 & 0 & 1 & 1 & 1 & 1 & 10 & \\
\hline & $\begin{array}{l}\text { Falta de recursos } \\
\text { humanos }\end{array}$ & 0 & 1 & 0 & 0 & 0 & 0 & 1 & 1 & 0 & 0 & 0 & 1 & 1 & 1 & 6 & \\
\hline & $\begin{array}{l}\text { Morosidade do poder } \\
\text { público }\end{array}$ & 0 & 0 & 0 & 0 & 1 & 0 & 1 & 1 & 0 & 0 & 0 & 0 & 0 & 0 & 3 & \\
\hline & SOMATóRIO & 32 & 30 & 21 & 21 & 18 & 23 & 24 & 22 & 0 & 4 & 7 & 13 & 13 & 13 & & \\
\hline & & & & & $\mathrm{e}$ & ais & iess & & & & nea & cas & nais & por & nte & & \\
\hline
\end{tabular}

Fonte: Dados da pesquisa, 2015.

A partir da tabela acima, pode-se inferir, então, que as potencialidades do cenário interno evidenciam as cinco forças mais atuantes com maior pontuação, como seguem:

$\checkmark$ Pesquisas sobre a região já realizadas (16); Presença de atributos histórico-culturais (15); Apoio e envolvimento de grupos de sociedade (14), Iniciativas já existentes de práticas turísticas (14); Paisagem notável (13), Localização estratégica com centros urbanos (13), Preservação dos recursos naturais (13); Alta geodiversidade (12).

Quanto às potencialidades das fraquezas mais debilitantes, foram apontadas as seguintes cinco mais pontuadas:

$\checkmark$ Falta de consciência da importância da área (10);Inexistência de infraestrutura (7); Falta de fiscalização (6), Dificuldade de fiscalização (6), Falta de consciência ambiental (6), Falta de recursos humanos (6); Inexistência de estudo de capacidade de carga (5); Ocupações irregulares (4), Falta de acessibilidade (4).

Neste sentindo, as cinco oportunidades mais pontuadas do cenário externo foram:

$\checkmark$ Potencial geoturístico e ecoturístico (32); Desenvolvimento de pesquisa (30); Conservação da área (24); Aumento da consciência ambiental (23); Capacitação de profissionais (22).

Sobre as cinco ameaças mais apontadas do cenário externo temos:

$\checkmark$ Ignorância sobre a conservação de geossítios (13), Interesses não conservacionistas (13), Turismo desordenado (13); Extrativismo (7); Especulação imobiliária (4).

Ciência e Sustentabilidade - CeS / Juazeiro do Norte, v. 3, n. 1, p. 94-123, jan/jun 2017 


\subsubsection{Matriz de Avaliação Estratégica de Parelhas}

A seguir, segue a tabela 5 com a Matriz de Avaliação Estratégica, em forma de Análise SWOT, para a área referente ao geossítios Açude Boqueirão, Mirador, localizados em Parelhas (RN).

Tabela 5: Matriz de Avaliação Estratégica de Parelhas.

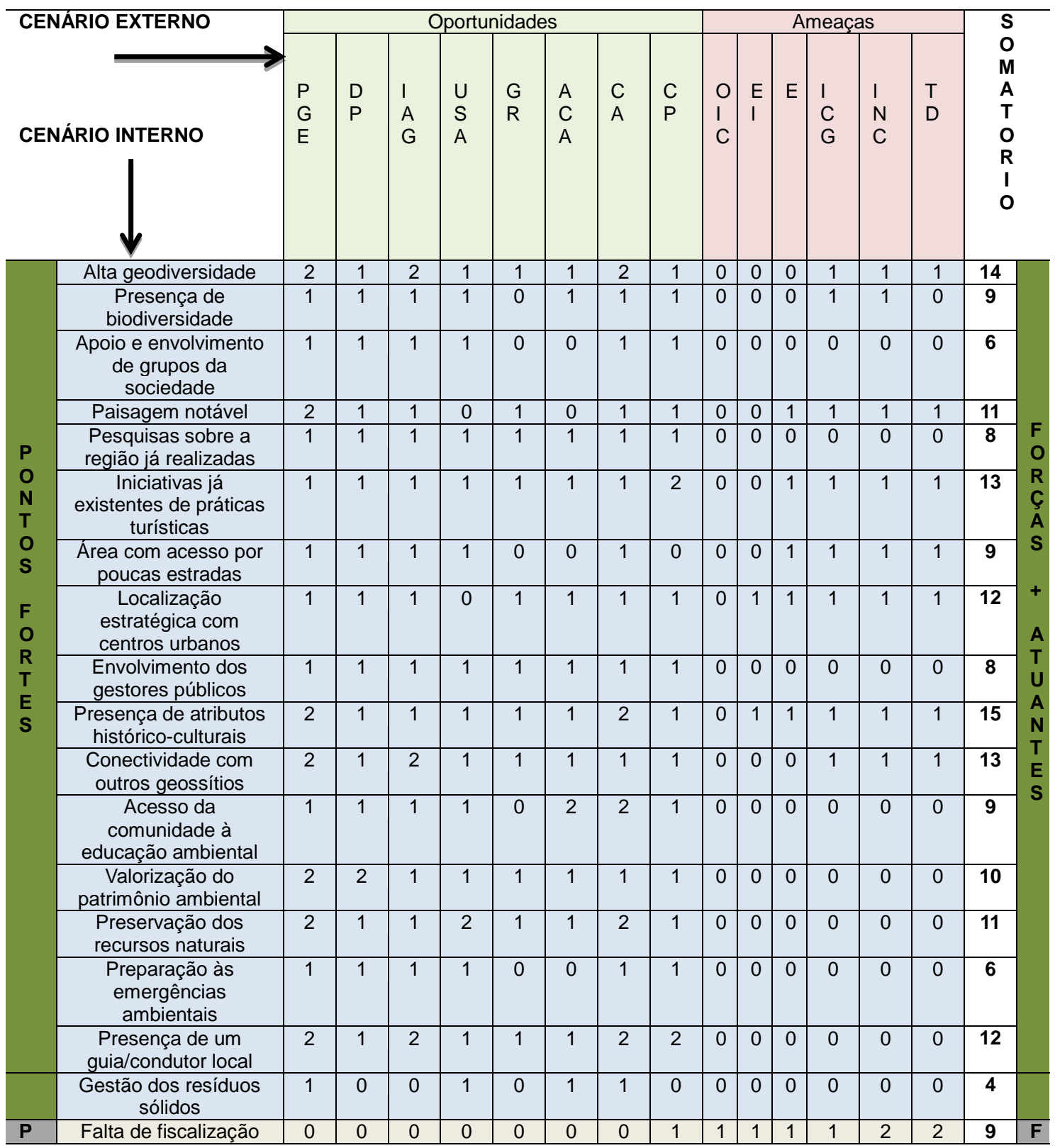

Ciência e Sustentabilidade - CeS / Juazeiro do Norte, v. 3, n. 1, p. 94-123, jan/jun 2017 
Janaina Luciana de Medeiros; Marcos Antonio Leite do Nascimento; André Riani Costa Perinotto

\begin{tabular}{|c|c|c|c|c|c|c|c|c|c|c|c|c|c|c|c|c|c|}
\hline $\begin{array}{l}\mathrm{O} \\
\mathrm{N}\end{array}$ & $\begin{array}{l}\text { Dificuldade de } \\
\text { fiscalização }\end{array}$ & 0 & 0 & 0 & 0 & 0 & 0 & 0 & 0 & 0 & 0 & 1 & 1 & 1 & 1 & 4 & $\begin{array}{l}\mathbf{R} \\
\mathbf{A}\end{array}$ \\
\hline $\begin{array}{l}\text { T } \\
0\end{array}$ & $\begin{array}{l}\text { Inexistência de } \\
\text { infraestrutura }\end{array}$ & 1 & 1 & 0 & 1 & 0 & 0 & 1 & 0 & 0 & 0 & 0 & 1 & 1 & 1 & 8 & Q \\
\hline $\begin{array}{l}S \\
F\end{array}$ & $\begin{array}{l}\text { Inexistência de estudo } \\
\text { de capacidade de } \\
\text { carga }\end{array}$ & 1 & 1 & 0 & 1 & 0 & 0 & 1 & 0 & 0 & 0 & 0 & 1 & 1 & 2 & 8 & $\begin{array}{l}\text { E } \\
Z \\
A\end{array}$ \\
\hline $\begin{array}{l}\mathbf{R} \\
\mathbf{A}\end{array}$ & Ocupações irregulares & 0 & 0 & 0 & 0 & 0 & 0 & 1 & 0 & 0 & 0 & 0 & 0 & 0 & 0 & 1 & s \\
\hline $\begin{array}{l}\text { C } \\
0\end{array}$ & $\begin{array}{c}\text { Falta de } \\
\text { acessibilidade }\end{array}$ & 1 & 1 & 1 & 1 & 0 & 0 & 1 & 0 & 0 & 0 & 0 & 0 & 0 & 0 & 5 & $\begin{array}{l}\text { D } \\
\text { E }\end{array}$ \\
\hline $\mathbf{S}$ & $\begin{array}{l}\text { Falta de consciência } \\
\text { ambiental }\end{array}$ & 1 & 0 & 0 & 1 & 0 & 0 & 2 & 0 & 0 & 1 & 1 & 1 & 1 & 1 & 9 & B \\
\hline & $\begin{array}{l}\text { Falta de recursos } \\
\text { financeiros }\end{array}$ & 0 & 0 & 0 & 0 & 0 & 0 & 1 & 2 & 0 & 0 & 0 & 0 & 0 & 0 & 3 & \\
\hline & $\begin{array}{c}\text { Falta de consciência } \\
\text { da importância da } \\
\text { área }\end{array}$ & 0 & 0 & 0 & 0 & 0 & 0 & 1 & 0 & 0 & 1 & 1 & 2 & 1 & 1 & 7 & \\
\hline & $\begin{array}{l}\text { Falta de recursos } \\
\text { humanos }\end{array}$ & 1 & 1 & 1 & 1 & 1 & 1 & 1 & 1 & 0 & 0 & 0 & 1 & 1 & 1 & 11 & \\
\hline & $\begin{array}{l}\text { Morosidade do poder } \\
\text { público }\end{array}$ & 0 & 0 & 0 & 1 & 1 & 0 & 1 & 1 & 0 & 0 & 0 & 0 & 1 & 1 & 6 & \\
\hline \multirow{2}{*}{\multicolumn{2}{|c|}{ SOMATÓRıO }} & 29 & 21 & 21 & 22 & 13 & 15 & 32 & 22 & 1 & 5 & 9 & 15 & 17 & 17 & & \\
\hline & & & & un & de & ais & ess & & & & \multicolumn{5}{|c|}{ mportante } & & \\
\hline
\end{tabular}

Fonte: Dados da pesquisa, 2015.

A partir da análise da tabela supracitada, percebeu-se que as cinco oportunidades das forças mais atuantes do cenário interno com maior pontuação foram:

$\checkmark$ Presença de atributos histórico-culturais (15); Alta geodiversidade (14); Iniciativas já existentes de práticas turísticas (13), Conectividade com outros geossítios (13); Localização estratégica com centros urbanos (12), Presença de um guia/condutor local (12); Paisagem notável (11); Preservação dos recursos naturais (11).

Já sobre as oportunidades das fraquezas mais debilitantes as cinco mais pontuadas foram:

$\checkmark$ Falta de recursos humanos (11); Falta de fiscalização (9), Falta de consciência ambiental (9); Inexistência de infraestrutura (8), Inexistência de estudo de capacidade decarga (8); Falta de consciência da importância da área (7); Morosidade do poder público (6).

Dessa forma, em relação às oportunidades do cenário externo temos como as cinco mais pontuadas:

$\checkmark$ Conservação da área (32); Potencial geoturístico e ecoturístico (29); Uso sustentável da área (22), Capacitação de profissionais (22); Desenvolvimento de pesquisa (21), Integração com outras áreas geoturísticas (21); Aumento da conscientização ambiental (15).

Ciência e Sustentabilidade - CeS / Juazeiro do Norte, v. 3, n. 1, p. 94-123, jan/jun 2017 
Com relação às ameaças mais importantes, as cinco mais pontuadas foram:

$\checkmark$ Interesses não conservacionistas (17); Turismo desordenado (17); Ignorância sobre a conservação de geossítios (15); Extrativismo (9); Especulação imobiliária (5); Ocupação irregular crescente (1).

\subsubsection{Matriz de Avaliação Estratégica de Carnaúba dos Dantas}

Abaixo, na Tabela 6, segue a Matriz de Avaliação Estratégica, em forma de Análise SWOT, para a área referente ao geossítios Monte do Galo e Xiquexique, localizados em Carnaúba dos Dantas (RN).

Tabela 6: Matriz de Avaliação Estratégica de Carnaúba dos Dantas.

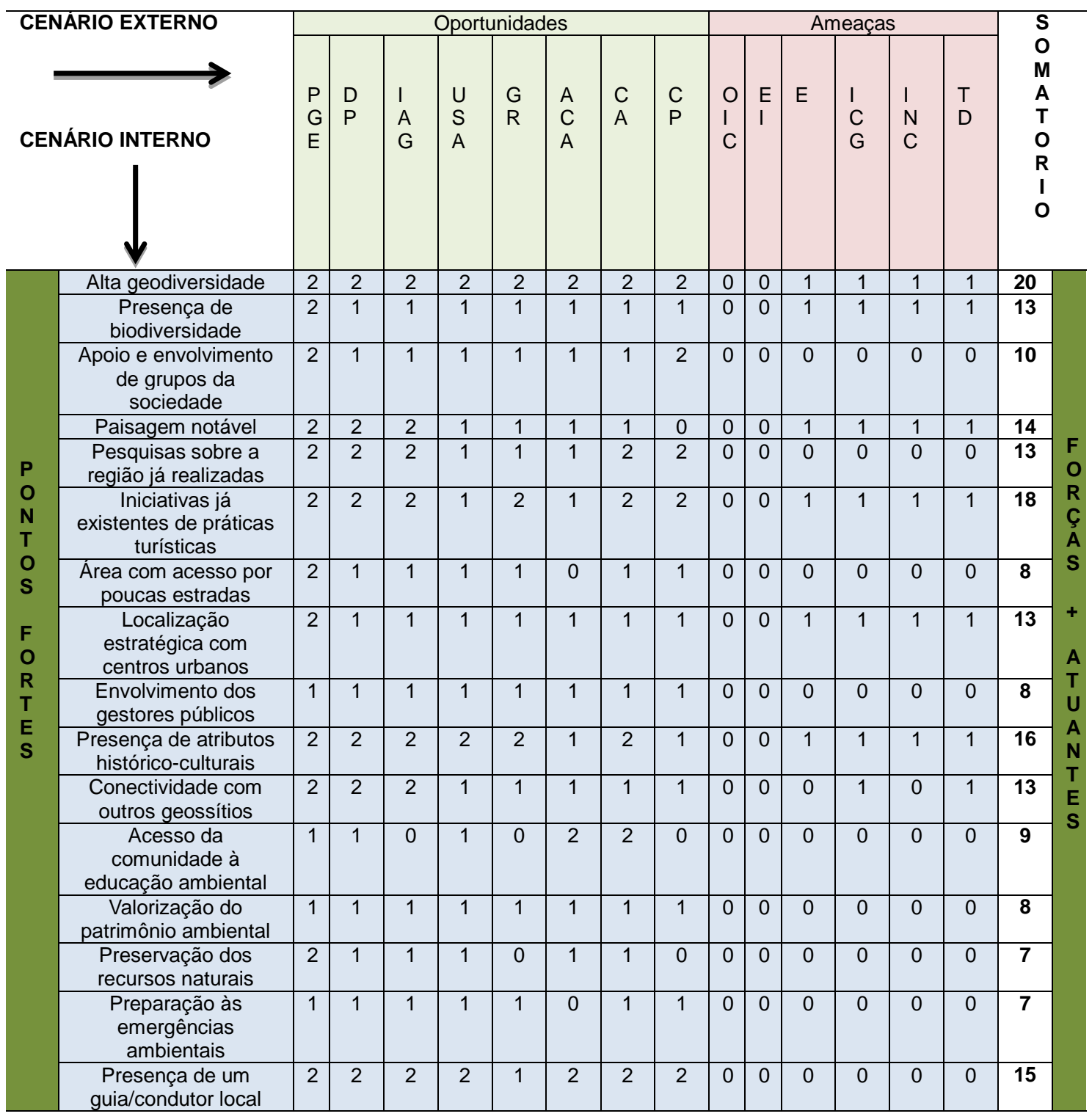

Ciência e Sustentabilidade - CeS / Juazeiro do Norte, v. 3, n. 1, p. 94-123, jan/jun 2017 


\begin{tabular}{|c|c|c|c|c|c|c|c|c|c|c|c|c|c|c|c|c|c|}
\hline & $\begin{array}{l}\text { Gestão dos resíduos } \\
\text { sólidos }\end{array}$ & 1 & 0 & 0 & 1 & 0 & 1 & 1 & 0 & 0 & 0 & 0 & 0 & 0 & 0 & 4 & \\
\hline $\mathbf{P}$ & Falta de fiscalização & 1 & 1 & 1 & 1 & 0 & 0 & 1 & 0 & 0 & 0 & 1 & 2 & 2 & 2 & 12 & $\mathbf{F}$ \\
\hline $\begin{array}{l}\mathrm{O} \\
\mathrm{N}\end{array}$ & $\begin{array}{l}\text { Dificuldade de } \\
\text { fiscalização }\end{array}$ & 1 & 1 & 1 & 1 & 0 & 0 & 0 & 0 & 0 & 0 & 0 & 1 & 1 & 1 & 7 & $\begin{array}{l}\mathbf{R} \\
\mathbf{A}\end{array}$ \\
\hline $\begin{array}{l}T \\
0\end{array}$ & $\begin{array}{c}\text { Inexistência de } \\
\text { infraestrutura }\end{array}$ & 1 & 1 & 1 & 1 & 0 & 0 & 1 & 1 & 0 & 0 & 0 & 0 & 0 & 0 & 6 & $\begin{array}{l}\mathbf{Q} \\
\mathbf{U}\end{array}$ \\
\hline $\begin{array}{l}S \\
F\end{array}$ & $\begin{array}{c}\text { Inexistência de estudo } \\
\text { de capacidade de } \\
\text { carga }\end{array}$ & 1 & 1 & 0 & 1 & 0 & 0 & 1 & 1 & 0 & 0 & 0 & 1 & 1 & 1 & 8 & $\begin{array}{l}\text { E } \\
Z \\
A\end{array}$ \\
\hline $\begin{array}{l}\mathbf{R} \\
\mathbf{A}\end{array}$ & Ocupações irregulares & 0 & 0 & 0 & 1 & 0 & 0 & 1 & 0 & 0 & 0 & 0 & 0 & 0 & 0 & 2 & $\begin{array}{l}S \\
+\end{array}$ \\
\hline C & $\begin{array}{c}\text { Falta de } \\
\text { acessibilidade }\end{array}$ & 1 & 1 & 0 & 0 & 0 & 0 & 1 & 0 & 0 & 0 & 0 & 0 & 0 & 1 & 4 & $\begin{array}{l}\text { D } \\
\text { E }\end{array}$ \\
\hline & $\begin{array}{c}\text { Falta de consciência } \\
\text { ambiental }\end{array}$ & 1 & 1 & 0 & 1 & 0 & 1 & 2 & 0 & 0 & 0 & 2 & 2 & 2 & 2 & 14 & $\begin{array}{l}B \\
\text { I }\end{array}$ \\
\hline & $\begin{array}{l}\text { Falta de recursos } \\
\text { financeiros }\end{array}$ & 0 & 1 & 0 & 0 & 1 & 0 & 1 & 1 & 0 & 0 & 0 & 0 & 0 & 0 & 4 & $\begin{array}{l}\text { L } \\
\text { I }\end{array}$ \\
\hline & $\begin{array}{c}\text { Falta de consciência } \\
\text { da importância da } \\
\text { área }\end{array}$ & 1 & 1 & 1 & 1 & 1 & 0 & 1 & 1 & 0 & 0 & 1 & 2 & 1 & 2 & 13 & $\begin{array}{l}\mathrm{A} \\
\mathrm{N} \\
\mathrm{T}\end{array}$ \\
\hline & $\begin{array}{c}\text { Falta de recursos } \\
\text { humanos }\end{array}$ & 1 & 1 & 1 & 1 & 0 & 0 & 1 & 2 & 0 & 0 & 1 & 1 & 1 & 1 & 11 & $\begin{array}{l}\mathrm{E} \\
\mathrm{S}\end{array}$ \\
\hline & $\begin{array}{l}\text { Morosidade do poder } \\
\text { público }\end{array}$ & 0 & 1 & 0 & 0 & 1 & 0 & 1 & 1 & 0 & 0 & 0 & 0 & 0 & 0 & 4 & \\
\hline & SOMATÓRIO & $\begin{array}{l}3 \\
7\end{array}$ & 33 & 27 & 28 & 20 & 19 & 34 & 25 & 0 & 0 & 11 & 16 & 14 & 17 & & \\
\hline
\end{tabular}

Fonte: Dados da pesquisa, 2015.

Da Tabela 6 exposta acima, pôde-se observar que em relação as potencialidades do cenário interno apontadas como forças mais atuantes temos as cinco mais pontuadas: Alta geodiversidade (20); Iniciativas já existentes de práticas turísticas (18); Presença de atributos histórico-culturais (16); Presença de um guia/condutor local (15); Paisagem notável (14).

Sobre as oportunidades das fraquezas mais debilitantes as cinco com pontuações maiores foram: Falta de consciência ambiental (14); Falta de consciência da importância da área (13); Falta de fiscalização (12); Falta de recursos humanos (11); Inexistência de estudode capacidade de carga (8).

As cinco mais pontuadas como oportunidades do cenário externo foram: Potencial geoturístico e ecoturístico (37); Conservação da área (34); Desenvolvimento de pesquisa (33); Uso sustentável da área (28); Integração como outras áreas geoturísticas (27).

Já as ameaças mais importante, as cinco que obtiveram maior pontuação foram: Turismo desordenado (17); Ignorância sobre a conservação de geossítios (16); Interesses não conservacionistas (14); Extrativismo (3).

Portanto, por meio dasMatrizes de Avaliação Estratégia, SWOT, desses municípios supracitados identificou-se um equilíbrio de fatores internos e externos que podem vir a influenciar no desenvolvimento do turismo. 
Neste sentido, pode-se inferir que os gestores necessitam apresentar esforços ao que se refere à definição de estratégias que contemplem o entorno dos geossítios, não somente como área física, mas considerando, também a questão social, promovendo, neste prisma, uma perspectiva que integre a comunidade e que ocorra uma gestão participativa.

Pode-se afirmar que a origem dos pontos fortes destacados nos geossítios estudados não dependem inteiramente da influência humana para que possa existir, sendo relacionados aos aspectos ambientais dessas áreas, como paisagem notável e de alta geodiversidade.

Outro ponto identificado no estudo foi a questão do turismo desordenado e o extrativismo, onde os moradores sabem da existência dos atrativos, mas em sua grande maioria não participam nas atividades desenvolvidas nesses locais. Este fato demonstra que a prática turística nas áreas estudadas pode ser uma alternativa viável de geração de emprego e renda para os moradores da região.

Mas, vale ressaltar que, segundo Valls (2006, p. 25) o desenvolvimento do turismo requer o envolvimento da sociedade em geral, entendida como o restante dos setores econômicos, sociais, culturais, ecológicos, esportivos etc. Os habitantes do destino são os primeiros interessados em conhecer a nova situação e em decidir sobre o desenvolvimento turístico da área, assumindo os benefícios e as desvantagens que ele traz. Essa coletividade e a rede de associações e instituições propiciam a auto adesão ao modelo de desenvolvimento. Se a maioria dos membros de uma sociedade não é favorável à orientação ao turismo de seu território, o processo gerará conflitos e disfunções a curto ou a longo prazo.

Assim, a área estudada apresenta problemas ambientais no que concerne ao seu uso público. Onde a falta de controle na questão do extrativismo por parte dos ceramistas tornou-se uma grande preocupação, pois se antes existia a mata fechada, hoje ao adentra-la se percebe muitas estradas construídas para a passagem de vários caminhões de lenha.

Sob este prisma, entende-se que o geoturismo seria uma prática para se minimizar esses efeitos, uma vez que, esse segmento prioriza os aspectos geológicos de uma localidade fazendo com que seja praticado um turismo de 
forma sustentável. Existe, pois, uma relação entre o turismo e a geomorfologia ${ }^{1}$ no sentido de despertar para os estudos realizados em áreas que são ou poderão se tornar atrativos turísticos, como por exemplos quedas d'água, rios, cavernas, entre outros lugares, sendo utilizadas por esta atividade para a maximização e valorização da gestão sustentável.

Para alguns estudiosos do geoturismo, esta atividade está relacionada com os recursos naturais muitas vezes negligenciados pelo ecoturismo, incluindo os aspectos geológicos e geomorfológicos, ou seja, os fatores abióticos, e pode ter, fundamentalmente, três motivações, sejam elas a recreação, o lazer e o aprendizado.

Em relação ao turismo ${ }^{2}$, o geoturismo consiste em uma denominação recente, com interesse de vários estudiosos na realidade mundial em relação a esta atividade.

Para Moreira (2008), o geoturismo é um dos mais novos segmentos de turismo em áreas naturais, assim as pessoas que realizam este tipo de prática tem em sua principal motivação o interesse nos aspectos geológicos e geomorfológicos de um determinado local.

Nesse contexto, o geoturismo pode ser entendido como uma aproximação das pessoas que possuem motivação intelectual em participar de atividades que envolvam aprendizado, exploração, descoberta e imaginação, tendo na interpretação um meio eficaz para absorver informações da geoconservação e geologia de forma acessível e de forma sustentável (MANOSSO, 2009).

Com relação ao que foi supracitado, o geoturismo possui objetivos que não são meramente contemplativos, apresentando uma finalidade didática, possibilitando constituir uma nova forma de oferecer instrumentos para a interpretação da herança da paisagem natural que permitem dialogar e compreender as particularidades geológicas e geomorfológicas dos lugares visitados (SILVA, 2007).

\footnotetext{
${ }^{1}$ A Geomorfologia é uma ciência que muito pode contribuir nessa etapa de planejamento, este se amparando nos instrumentos legais hoje existentes, haja vista que o relacionamento do turismo com o meio ambiente está longe de ser simples.

${ }^{2} \mathrm{O}$ importante nessa relação entre o turismo e a geomorfologia é que esta última, além de conferir cientificidade à contemplação turística, serve também como instrumento de planejamento, ajudando a ordenar a atividade turística e a torná-la mais viável e sustentável.
} 
Dessa forma, o geoturismo dá destaque ao meio abiótico, ou seja, a geodiversidade da região visitada, promovendo o desenvolvimento do segmento de forma a conservar o patrimônio natural, histórico e cultural, destacando nos visitantes o fascínio pela história do Planeta Terra (ROCHA e NASCIMENTO, 2007).

Assim, percebe-se que a prática do geoturismo vai além da utilização dos aspectos geológicos como um atrativo turístico, esse segmento também busca a geoconservação e a sustentabilidade do local que está sendo visitado (MANOSSO, 2009).

O geoturismo, em sua essência, deve utilizar os aspectos geológicos na promoção de uma interpretação ambiental e cultural da área, gerando benefícios para a comunidade local. Nesta perspectiva, uma prática que faz com que muitos turistas que não possuem conhecimentos sobre a geologia veem seus aspectos como um componente interessante da paisagem, não havendo somente a apreciação da paisagem, mas também sua compreensão (caso sejam fornecidos meios para que haja esta compreensão). Todavia, para que haja este entendimento, o turista deve ter interesse em ver a natureza com outros olhos, compreendendo o acervo geológico local.

A necessidade de conservar e valorizar a geodiversidade de um local, por sua vez, despertou em algumas pessoas a preocupação em identificar e visitar áreas com atrativos geoturísticos, bem como de entender como ocorreu a formação do planeta, algumas formas de relevo, sendo o turismo mais que uma atividade contemplativa, mas participativa e científica.

Além disso, a necessidade de o homem procurar por ambientes naturais fazem surgir segmentos cada vez mais diversificados na prática de turismo nesses ambientes. Sendo assim, diante desse cenário, cresce a cada dia a prática do geoturismo que, além de se utilizar dos aspectos geológicos de uma determinada região, busca promover a interpretação ambiental e cultural, além do benefício que propicia para a comunidade dessa área.

Nesse sentido, Mc Keever et al(2006) apud Moreira (2008) afirmam que o geoturismo, se for comparado com outros segmentos turísticos, ainda está iniciando sua história, com destaque particular na conservação, educação e atrativos turísticos em relação aos aspectos geológicos, no qual ocorre a interpretação do ambiente em relação aos processos que o modelaram através 
do uso de uma ferramenta específica: a educação ambiental. Ela possibilita um melhor aproveitamento dos recursos que a natureza oferece, dando suporte para a conservação e as possibilidades de aproveitar melhor dos recursos para suas atividades.

Mas vale ressaltar que o geoturismo, não é só contemplar os aspectos geológicos de um determinado local, ele busca a prática de um turismo de forma sustentável, ou seja, é preciso entender que se trata de um turismo que mantém ou aprimora o caráter geográfico de um local - seu meio ambiente, geologia, cultura, estética, patrimônio e o bem-estar de seus moradores. Isso é diferente de turismo geológico. A geodiversidade é o principal atrativo do geoturismo, porém só é considerado como tal se a comunidade tiver envolvida e efetivamente participar das ações. Já o turismo geológico está relacionado simplesmente a visitas a locais de interesse geológico. Além disso, no geoturismo podemos promover: educação territorial, valorização do patrimônio (geológico, cultural etc) e sustentabilidade.

Outrossim, existem vários modos de proteção que podem ser adotadas no meio ambiente, como por exemplo, a adoção de técnicas de praticar a educação ambiental, começando pela comunidade local bem como inserindo na atividade turística, o que proporcionaria maior participação da população na atividade, contribuindo com novas fontes de renda e consequentemente agindo pro ativamente no desenvolvimento da própria localidade.

No que se refere a elaboração das Matrizes de Avaliação Estratégica em forma de SWOT dos municípios do Projeto Geoparque Seridó, evidenciou-se que ao recorrer à análise e caracterização dos fatores expostos nessas matrizes, foi possível obter um diagnóstico contemplando a capacidade e a necessidade de intervenção desses elementos nos locais estudados, possibilitando levantar as potencialidades turísticas das localidades, sob uma ótica mais ampliada sobre o que está acontecendo e como se encontram os geossítios e sua relação com o turismo até o momento.

Partindo desses princípios supracitados se pensou como contribuição dessa pesquisa sugerir ações, para os gestores que buscam trabalhar com esses locais, visando melhorias na conservação dos geossítios analisados. Vale ressaltar que, tais diretrizes foram pautadas na realidade vivenciada através dos métodos empregados na área desse estudo, como também, nas 
pesquisas realizadas, assim como, se buscou diretrizes do Programa Nacional de Educação Ambiental - ProNEA, e no documento Diretrizes para a Visitação em Unidades de Conservação, bem como, as estratégias de geoconservação. As principais ações são:

- Elaborar o Plano de Manejo das áreas estudadas, levando em consideração os resultados de pesquisas científicas, as potencialidades e fragilidades do ambiente, bem como os impactos de visitação;

- Aplicar metodologias de capacidade de carga nos geossítios;

- Incentivar, promover e fortalecer a participação e corresponsabilidade dos atores interessados na prática turística na região do Seridó, como comunidades locais, agências de turismo, associações locais, poder público, poder privado, etc.;

- Incentivar a participação da comunidade local na elaboração e gestão de um plano turístico para os municípios do Projeto Geoparque Seridó, incentivando a auto-gestão da atividade;

- Apoiar as pesquisas científicas nesses locais e entorno, e usar seus resultados como subsídios para a tomada de decisões;

- Propiciar a formação de monitores/condutores especializados na disseminação de geoinformações pertinentes aos geossítios para turistas e visitantes;

- Desenvolver e implementar ações e projetos de educação ambiental as atividades de visitação nos geossítios, visando minimizar os impactos negativos do turismo e garantir os usos e atividades na área sejam compatíveis com os objetivos do Projeto Geoparque Seridó;

- Monitorar os impactos da visitação nesses locais, por meio da criação de um Sistema de Monitoramento de Impactos da Visitação que determine, dentre outros aspectos, um sistema de agendamento das visitações e a capacidade de carga da área;

- Buscar o estabelecimento de uma infraestrutura e equipamentos para atender aos visitantes, adequados as características de cada geossítios;

- Implantar as lixeiras para a coleta seletiva de lixo em lugares estratégicos dos geossítios, para a disposição dos resíduos provenientes das atividades turísticas nos locais; 
Janaina Luciana de Medeiros; Marcos Antonio Leite do Nascimento; André Riani Costa Perinotto

- Promover parcerias com instituições do governo, de ensino, da sociedade cível e da iniciativa privada, a fim de alcançar os objetivos do Projeto Geoparque Seridó e adequar à visitação aos princípios da sustentabilidade;

- Disponibilizar informações aos visitantes antes e durante a visitação, de forma que eles possam prevenir acidentes, minimizar os impactos naturais e culturais que causam e asseguram a qualidade de suas experiências;

- Desenvolver campanhas de informações, sensibilização e educação ambiental que possam aproximar a população local dos municípios do Projeto Geoparque Seridó e despertar sentimentos de respeito e responsabilidade frente à área;

- Identificar possíveis riscos à segurança, à saúde dos visitantes e à proteção da geodiversidade dos geossítios no Projeto Geoparque Seridó;

- Praticar normas, princípios, códigos e padrões de conduta segura, ao visitante e ao meio ambiente e incentivar que os atores envolvidos com a atividade turística também o façam;

- Elaborar, em conjunto com os órgãos responsáveis, um plano de operações emergenciais, a fim de reagir prontamente a qualquer tipo de emergência, e uma cartilha com recomendações à segurança dos visitantes e que informe, também, os riscos inerentes a cada local aberto à visitação e a cada atividade que pode ser desenvolvida em cada geossítio;

- Oferecer palestras e cursos de formação sobre segurança e conduta consciente de visitação aos atores envolvidos com as práticas nos geossítios;

- Promover palestras com a comunidade local, guias de turismo e condutores, assim como os demais atores que trabalham com as áreas dos geossítios a fim de conscientizar da importância desses locais para o desenvolvimento do turismo para o município e região;

- Proporcionar cursos de capacitação na área turística para a comunidade que fazem parte desses municípios, como o propósito de oportunizar uma melhoria no mercado de trabalho para essas comunidades e com isso, contribuir para o crescimento do turismo na região;

- Promover palestras/cursos sobre as estratégias de geoconservação, com o intuito de efetivar a proteção dos geossítios, a conscientização da população e autoridades, a "geoeducação" de crianças, jovens e adultos, bem 
como, o estímulo ao turismo sustentável e a valorização das atividades, costumes e produtos locais;

- Utilizar, desenvolver e empregar instrumentos de interpretação ambiental, como forma de estimular o visitante a desenvolver a consciência, a apreciação e o entendimento dos aspectos naturais e culturais, fundamentados em pesquisas e informações, minimizando os impactos negativos dessa visitação, e transformando a visita aos geossítios numa experiência enriquecedora e agradável.

Ressalta-se, porquanto, que, o planejamento turístico é considerado por estudiosos como uma variável indispensável para a obtenção do sucesso em qualquer atividade. Contudo, as observações realizadas nesses municípios evidenciaram que este elemento não é posto em prática de forma pontual, sendo utilizado apenas para suprir a interesses específicos, propiciando o desenvolvimento da atividade turística de forma desarranjada e com pouca responsabilidade ao que se refere à sustentabilidade.

\section{CONSIDERAÇÕES FINAIS}

A referida pesquisa demonstrou que, os atores que pretendem trabalhar com a prática do turismo visando a utilização da geodiversidade comoum produto turístico integrador através dos geossítios inseridos nos municípios desseprojetodevem apresentar esforços maiores nas definições de estratégias de envolvimento com práticas ambientais que busquem, não apenas a área física, mas também no âmbito social, promovendo uma perspectiva integradora e participativa de gestão na busca de se alcançar um desenvolvimento sustentável, não só localmente, mas priorizando os aspectos geológicos da região, no sentido de que seja praticado um turismo de forma sustentável, no qual há uma relação direta no despertar de uma maximização e valorização da área desse estudo.

Diante do exposto, a região estudada apresenta problemas no que tange a conservação dos geossítios, assim como, a falta de consciência ambiental. Ficando evidenciado pela ausência de investimentos por parte dos órgãos responsáveis e a falta de consciência da importância da área também das 
populações locais e dos visitantes que utilizam seus recursos de forma inadequada.

Espera-se que esta pesquisa tenha contribuído para identificar os principais problemas que acarretam nos geossítios do Projeto Geoparque Seridó/RN, assim como, ter possibilitado obter dados da atual conjuntura da atividade turística voltada à geodiversidade nos municípios dessa proposta, e com isso, despertar nos planejadores de turismo local a intenção da elaboração e o planejamento sustentável para promover cada destino turístico, sempre com base nos princípios da sustentabilidade, na busca de conservá-los para que as gerações futuras possam conhecer e continuar a desenvolver a atividade turística.

Dessa maneira, todos os objetivos propostos no início do trabalho foram atendidos e possibilitaram o sucesso de atingir as perspectivas imaginadas no levantamento do objetivo geral da presente pesquisa.

Até a conclusão dessa pesquisa enfrentou-se algumas dificuldades referentes a falta de guias ou condutores em alguns geossítios analisados, assim como, a falta de informação e conhecimento de alguns dados por partes dos gestores entrevistados.

É pertinente ressaltar que essa pesquisa não encerra o estudo, ao contrário, serve de base para a execução de novos trabalhos, cada vez mais aprofundados sobre o referido tema.

Concluiu-se, portanto, que na procura por promover a sustentabilidade atrelada à atividade turística é indispensável que os destinos turísticos sejam avaliados conforme seu contexto e suas demandas locais específicas. Ao ponto que, os atores desse processo necessitam procurar se adequar às ações, objetivando o desenvolvimento de acordo com as possibilidades desse destino, onde os sistemas de indicadores devem ser adaptados à realidade local de forma a possibilitar uma prática turística sustentável.

\section{REFERÊNCIAS}

ALVES, I.; REZENDE, S. O.; NETO, O. J. de O.; DREES, C.; SANTANA, R. Aplicação do Modelo e Análise SWOT no Diagnóstico Estratégico de uma Propriedade Rural Especializada em Recria e Engorda de Bovinos de Corte. Revista administração-ação, n4, 2007, p. 22-39. 
AZEVEDO, M.; COSTA, H. Métodos para avaliação da Postura Estratégica. Caderno de Pesquisas em Administração, v8,nํ2, abr/jun., 2001, p. 1-18.

BANZATO, B. de M.; FAVERO, J. M.; AROUCA, J. A. C.; CARBONARI, J.H.B. Análise ambiental de unidades de conservação através dos métodos SWOT e GUT:O caso do Parque Estadual Restinga de Bertioga. Revista Brasileira de Gestão Ambiental, v. 6, №1, jan/dez. 2012, p. 38-49.

DANTAS, N. G. de S.; MELO, R. de S. O método de análise SWOT como ferramenta para promover o diagnóstico turístico de um local: o caso do município de Itabaiana/PB. Caderno Virtual de Turismo, vol. 8, nํ 1, 2008.

DUBRIN, A.J. Princípios de administração. Rio de Janeiro: LTC, 1998.

FONSECA, T. A. A. L. C. da. O paradigma do planejamento de emergência de proteção civil em Portugal. 2010, 313 f. Dissertação (Mestrado em Dinâmicas Sociais, Riscos Naturais e Tecnológicos) - Faculdade de Economia, Universidade de Coimbra, Coimbra, 2010.

LOBATO, D.M., et al. Estratégia de empresas. Rio de Janeiro: Editora FGV, 2004.

LOUREIRO, N. C. V. O posicionamento da marca Vinho do Porto no panorama nacional. 2011. 106f. Dissertação (Mestrado em Gestão das Organizações) - Instituto Politécnico de Bragança, Bragança, 2011.

MACHADO, R. T. M. Estratégia e competitividade em organizações agroindustriais. Lavras: UFLA/FAEPE, 2005.

MANOSSO, F. C. Geoturismo: uma proposta teórico metodológica a partir de um estudo de caso do município de Apucarana-PR. Caderno Virtual de Turismo, Rio de Janeiro, v.7, n. 2. 2009.

MINTZBERG, $H$., et al. Safári de estratégia: um roteiro pela selva do planejamento estratégico. Porto Alegre: Bookman, 2000.

MOREIRA, J. C. Patrimônio geológico em unidades de conservação: atividades interpretativas, educativas e geoturísticas. 2008. Tese (Doutorado em geografia) - Universidade Federal de Santa Catarina, Florianópolis, 2008. PETROCCHI, M . Gestão de polos turísticos. São Paulo: Futura, 2001. 
ROCHA, J. C. A. da; NASCIMENTO, M. A. L. O Pico do Cabugi como produto ecoturístico e geoturístico no Rio Grande do Norte. Global Tourism, [s.l.], v. 3, n. 2. 2007.

SILVA, F. R. A paisagem do Quadrilátero Ferrífero, MG: Potencial para o uso turístico da sua geologia e geomorfologia.144f. Dissertação (Mestrado em Geografia) -Departamento de Geografia, Universidade Federal de Minas Gerais, Belo Horizonte, 2007.

SILVEIRA, A.D., et al. Um passo além da terceirização: a transferência de atividades etecnologia. - Porto Alegre: Badejo Editorial, 2002.

TEIXEIRA, S. Planeamento, gestão das organizações. 2ed. Lisboa: McgrawHill, 2005.

TRAPP, S. R. B. Análise estratégica da terceirização de serviços de engenharia: Caso Vega do Sul. 2005. 114f. Dissertação (Mestrado em administração) - Programa de Administração de Empresas, Universidade do Estado de Santa Catarina, Florianópolis, 2005.

VALLS, Josep-Francesc. Gestão integral de destinos turísticos sustentáveis. Rio de Janeiro: Editora FGV, 2006. 